\title{
Multi-modal Bio-metrics Evaluation for Non-destructive Age States Determination of Tomato Plants (Solanum lycopersicum)
}

\author{
Muhammad Makky \\ \# Department of Agricultural Engineering, FATETA, Andalas University, Padang 25163, West Sumatera, Indonesia \\ E-mail:muh_makky@yahoo.com
}

\begin{abstract}
Every plant has unique morphological features, and can be used for its characteristics identity, such as age. When the plants grow, their morphological features may change, observable visually or by optical equipment. These various morphology transformations were categorized as multi-modal Bio-metrics. In this study, tomatoes from local cultivar were grown in a net house, in west Sumatra. The growth medium comprised of soil, husk, and manures with the composition of 1: 1: 1 respectively. For best growth, plants were watered regularly, and protect from pests and weeds. The observations were performed on 21st, 42nd, and 63rd day after sowing (DAS). The samples were the leaflets of the primary compound leaves of the plants. The leaflets were cut and digitized using a high-resolution colour scanner. The imaging performed at $\mathbf{3 0 0}$ dpi resolution, and the recorded image subsequently processed by the image processing software. Image segmentation performed to remove background from the object. Furthermore, the greenish of leaf object in the image were measured in RGB colour space. The leaf dimensions and area were quantified by the software, as well as the length of the leaflet main vein at central axis. Two secondary leaflet's blades were selected manually, and the angle formed between the blades and the main vein was measured. A Statistical engineering program was used to identify the principal morphology characteristics of the leaf, by means of Principal component analysis (PCA). Mathematical models were developed based on the principal component values and leaflets position to determine the plants age and state. Results showed all model have coefficient of correlation higher than 0.99 indicating acceptable accuracy.
\end{abstract}

Keywords — Non-destructive; Tomato leaf; Digitizing; Age states of plants; Morphology.

\section{INTRODUCTION}

The tomatoes are widely cultivated in Indonesia, as one of the local horticultural products, and generally used for domestic consumption. The annual production of tomatoes in Indonesia reached more than 800 thousand metric ton [1], where the centre of production located in the West Java province.

During the plants' growth, the physical and biological characteristics of the tomato plants are changing. This transformation can be used for phenotypic, among others, to observe the age and developmental stages of the plant. The plant's age is closely related to methods of treatment, as well as the necessity for water and other nutrients [2].

Phenotypic of tomato plants can be performed, among other, by observing the changes of physical and biological characteristics of the plants, such as through Multimodal Biometric analysis of the plant's components [3]. This method has been widely used to perform identification and classification of various types of plants [4]. Unlike the systems for human biometric analysis, which widely available on the market, similar systems for plants analysis were seldom, and more often still under developments. Each plant characteristic is unique and identifiable at a species level [3]. Therefore specific system needs to be developed for each species, including tomato.

Several multimodal biometric system have been developed to find various characteristics of plants, such as image analysis of canopy plants [5],[6], plant spacing and field slope [7],[8], plant shape [9], Ichnography [10], Hemispherical photography [11],[12], plant truss [9], and chlorophyll fluorescence imaging for plants [13] as well as for tomato canopy [14]. However, most of these methods cannot directly applied in the field, since they requires special tools and techniques for implementation.

For more practical and workable approach, the applications of multimodal biometric analysis for plants were focused on the leaves of the plants, such as the study by Raza et al. [15],[16], Oerke et al. [17],[18], and Lindenthal et al. [19]. Structural analysis of the leaves of tomato plants allows traceability of integration lines in domestic plants from wild species [20]. In addition, the same analysis revealed an interesting association between leaf morphology and sugar accumulation in tomato fruits.

Several important parameters of the leaves that can be used for multimodal biometric analysis include the leaflet's 
basic geometric features [21], colour [22], texture [23], and shape [24].

The requirements for nutrients, water, and treatment for plants, Tomato in particular, will vary according to the developmental stages of the plant. Providing these necessities in the right amounts will encourage excellent growth rates, and at the same time will improve plant productivity. In parallel, the exact dosage of fertilizer and water in particular, will significantly reduce overall production costs, as well as environmental consequences in cultivation practice, since the excess nutrients will accumulate and eventually contaminate the soil in the production area.

In this study, multimodal biometric analysis techniques will be used to analyse the geometrical features of the leaflets of the tomato plants for plant's age determination. These leaflets of the primary compound leaves of the plants' were selected at certain positions and the plants were cultivated precisely including the application of the fertilizer, water, and plants treatment appropriately given to prevent excessive dosages.

The results of this study can be used by the local community, especially tomato farmers, to cut their production costs, while in the same time increase productivity, efficiency and competitiveness, to enhance their chance in the ASEAN Economic Community 2015.

\section{MATERIAL AND METHODS}

A simple net house with the dimension of 6 by 4 by $1.8 \mathrm{~m}$ (length, width, high) was built to accommodate the samples. The study was performed in Padang (S 0 ${ }^{\circ} 55^{\prime} 38.4126^{\prime \prime}$, E $\left.100^{\circ} 27^{\prime} 42.3504 "\right)$, West Sumatra, Indonesia. Local tomato seeds were sown in 30 polybags, each one litre size. The growth medium was a mixture, comprised of top soil, husk, and manures with the composition of 1: 1: 1 respectively. Before sowing, the mixture was watered until the water in soil reached field capacity. Each polybag was sown two tomato seeds, by immersing the seed one $\mathrm{cm}$ inside the media, as measured from the surface. The polybags were placed in shaded area in the net house. Seven days after sowing, observation was performed to replaced non-grow seeds. At the same time, thinning was performed by removing second plant in each polybag. The weeding was done subsequently.

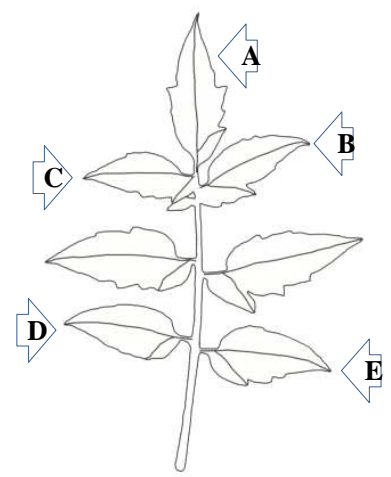

Fig. 1. Five Leaflets from Every Terminal Compound Leaf Were from the Tomato Plant for Imaging to be digitized for The Geometrical Measurements.

The polybags positioned in the net-house with $50 \mathrm{~cm}$ space between plants. Plants treated and watered regularly, and weeds are regularly removed. On day 21 , the primary compound leaves from plants were cut and its leaflets separated. Five leaflets from the compound leaves (top, 2 upper and 2 basal) were measured (Fig. 1) and digitized by means of imaging process, using digital colour flatbed scanner. The scanner resolution was set to $600 \mathrm{dpi}$ in order to preserve features information of the leaflets. The images were segmented by removing the background using image processing program (Fig. 2). The software was made using the C\# programming language. Subsequently after segmentation, image was threshold and leaflet colour was measurement consecutively, automatically by the image processing program.

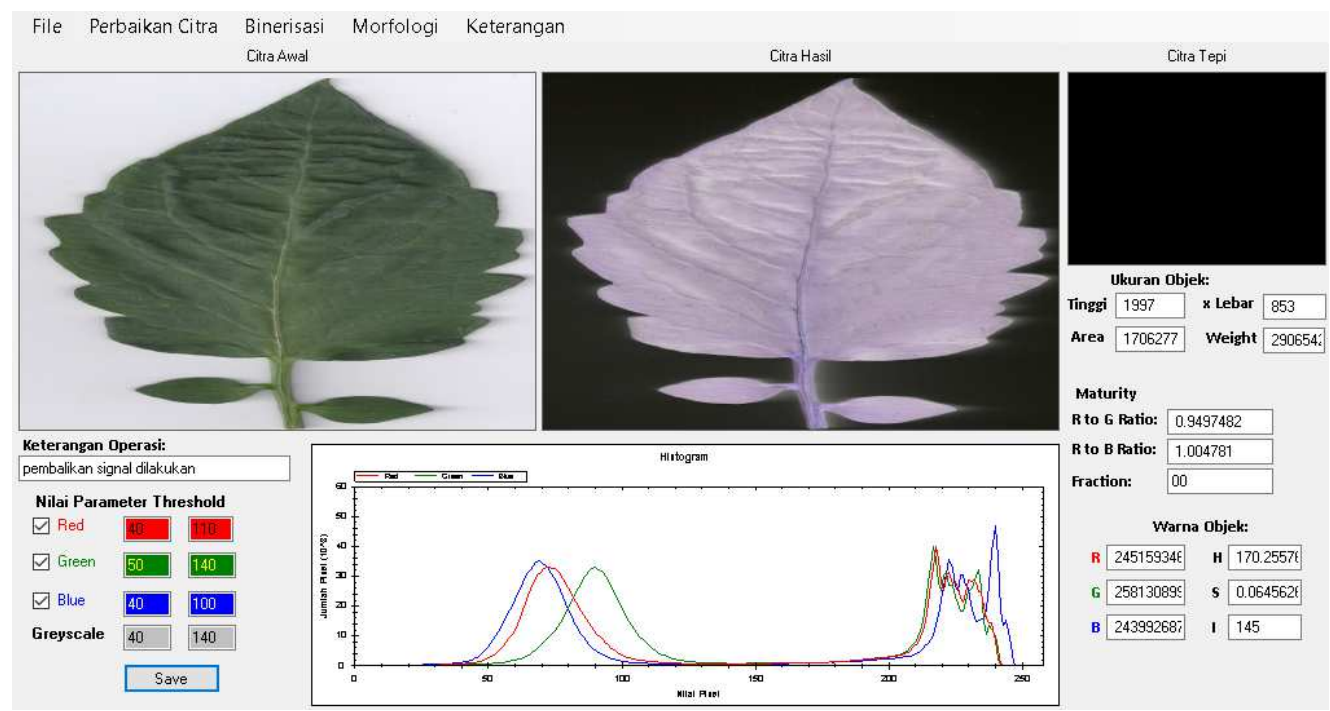

Fig. 2. Image Processing Program for Tomato Leaflets Multimodal Biometric Analysis 
Multimodal biometric analysis of the plants leaflets were performed by phenotypic eight basic geometric features [21] of leaf (Fig. 3). The leaf colour also included in the observation [22], and considered as loose biometric parameter. Although leaf texture [23], and shape [24] can be considered as biometric parameters, in this study both parameters were not included for practical reason.

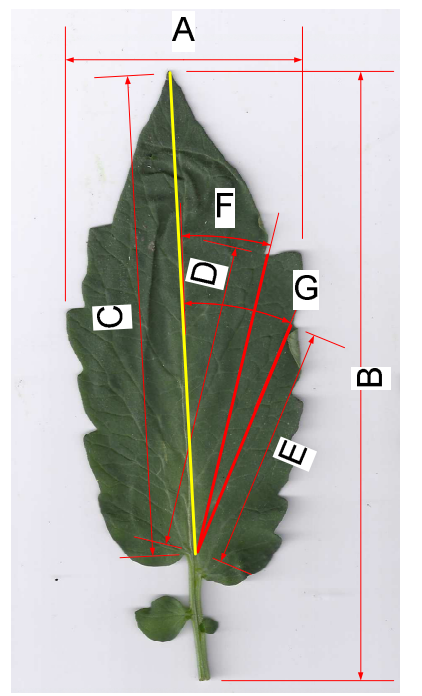

Fig. 3. Geometrical Features of the Leaflet Considered as Biometric Parameters in This Study: Width (A); Length Including Petiole (B); Main Vein Length $(\mathrm{C}) ; 1^{\text {st }}$ Blade Length (D); And Its Angle to The Main Vein (F); $2^{\text {nd }}$ Blade Length (E); and Its Angle to The Main Vein $(G)$.

Imaging of the leaflets were performed on 21 days after sowing (DAS) and repeated on 42 and 63 DAS. On each observation, 10 tomato plants were used as samples, and in total 30 plants were used as samples in this study.

A Statistical engineering program was used to find the principal morphology factor of the leaf, by means of Principal component analysis (PCA). The program was used to determine which of eight biometric parameters will be considered as the important parameters for multimodal analysis. The coefficients of the principal components obtained from the PCA were used to calculate the principal component values.

Mathematical models were developed to determine the plants' age using regression analysis. This analysis was performed by means of graphs to explain the relationship between plants age and its multimodal biometric parameters, as well as the accuracy of the models.

\section{RESULTS AND DISCUSSION}

The multimodal biometric dimensions data of the sample plants as measured in this study were presented in Table 1. The Table showed a positive relationship between geometrical features dimension and plants' age. As the plants grow, most of its components gain in size, except the angle formed between the leaf blades with the main vein $(F$ and $\mathrm{G}$ in Fig. 3). The rate of grow of the geometrical components of the leaflets in relation to the plants' age represented in Fig. 4.

TABLE I

BIOMETRIC PROPERTIES OF THE TOMATO LEAVES ACCORDING TO GEOMETRIC FEATURES AND PLANT's AGE

\begin{tabular}{|c|c|c|c|c|c|c|c|c|}
\hline \multirow{2}{*}{ 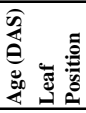 } & \multirow[b]{2}{*}{$\begin{array}{l}\text { Veins }^{\mathrm{z}} \\
(\mathrm{mm})\end{array}$} & \multirow[b]{2}{*}{$\begin{array}{l}\text { Wide }^{\mathrm{z}} \\
(\mathrm{mm})\end{array}$} & \multirow[b]{2}{*}{$\mathbf{L A}^{\mathbf{z}}\left(\mathbf{m m}^{2}\right)$} & \multicolumn{2}{|c|}{ 1st Leaf Blade ${ }^{\mathrm{z}}$} & \multicolumn{2}{|c|}{ 2nd Leaf Blade ${ }^{z}$} & \multirow[b]{2}{*}{$\begin{array}{l}\text { Petiole }^{\mathrm{z}} \\
\text { (mm) }\end{array}$} \\
\hline & & & & $\begin{array}{l}\text { Length } \\
(\mathrm{mm})\end{array}$ & Angle ${ }^{0}$ & $\begin{array}{l}\text { Length } \\
(\mathbf{m m})\end{array}$ & Angle $^{0}$ & \\
\hline $21 \mathrm{a}$ & $31 \pm 0.8_{a b}$ & $13 \pm 0.3_{b}$ & $\quad 201.5 \pm 5_{\mathrm{ab}}$ & $16 \pm 0.4_{b}$ & $11.8 \pm 0.3_{\mathrm{at}}$ & b $9 \pm 0.2_{b}$ & $23.3 \pm 0.6_{\mathrm{ab}}$ & $5 \pm 0.1_{\mathrm{a}}$ \\
\hline b & $30 \pm 0.8_{\mathrm{ab}}$ & $11 \pm 0.3_{\mathrm{a}}$ & $165 \pm 4.1_{\mathrm{a}}$ & $17 \pm 0.4_{b}$ & $15.8 \pm 0.4_{\mathrm{al}}$ & $5 \pm 0.1_{\mathrm{a}}$ & $33.8 \pm 0.8_{\mathrm{b}}$ & $0_{a}$ \\
\hline c & $33 \pm 0.8_{\mathrm{b}}$ & $14 \pm 0.4_{b}$ & $231 \pm 5.8 \mathrm{~b}$ & $17 \pm 0.4_{b}$ & $7.1 \pm 0.2$ & $\mathrm{a} 11 \pm 0.3_{\mathrm{b}}$ & $14.9 \pm 0.4_{\mathrm{a}}$ & $0_{a}$ \\
\hline d & $25 \pm 0.6_{\mathrm{a}}$ & $12 \pm 0.3_{\mathrm{a}}$ & $150 \pm 3.8 \mathrm{a}$ & $11 \pm 0.3 \mathrm{a}$ & $15.1 \pm 0.4_{\mathrm{at}}$ & b $9 \pm 0.2 b$ & $29.6 \pm 0.7_{b}$ & $5 \pm 0.1_{\mathrm{a}}$ \\
\hline $\mathrm{e}$ & $26 \pm 0.7_{\mathrm{a}}$ & $11 \pm 0.3_{\mathrm{a}}$ & $143 \pm 3.6_{\mathrm{a}}$ & $12 \pm 0.3 \mathrm{a}$ & $22.7 \pm 0.6$ & ${ }_{\mathrm{b}} 8 \pm 0.2_{\mathrm{b}}$ & $39 \pm 1_{b}$ & $4 \pm 0.1_{\mathrm{a}}$ \\
\hline $42 \mathrm{a}$ & $88 \pm 2.2_{\mathrm{d}}$ & $37 \pm 0.9_{\mathrm{d}}$ & $1628 \pm 40.7_{d}$ & $63 \pm 1.6_{d}$ & $7.2 \pm 0.2$ & $\mathrm{a} 48 \pm 1.2_{\mathrm{d}}$ & $14.3 \pm 0.4_{\mathrm{a}}$ & $0_{\mathrm{a}}$ \\
\hline $\mathrm{b}$ & $80 \pm 2_{\mathrm{cd}}$ & $38 \pm 1_{d}$ & $1520 \pm 38_{\mathrm{d}}$ & $58 \pm 1.5_{\mathrm{d}}$ & $8.1 \pm 0.2$ & a $46 \pm 1.2_{d}$ & $18.3 \pm 0.5_{\mathrm{a}}$ & $0_{\mathrm{a}}$ \\
\hline $\mathrm{c}$ & $80 \pm 2_{\mathrm{cd}}$ & $35 \pm 0.9_{\mathrm{d}}$ & $1400 \pm 35_{\mathrm{d}}$ & $49 \pm 1.2_{\mathrm{ed}}$ & $11.1 \pm 0.3_{\mathrm{at}}$ & ${ }_{\mathrm{b}} 37 \pm 0.9_{\mathrm{cd}}$ & $17.5 \pm 0.4_{\mathrm{a}}$ & $0_{\mathrm{a}}$ \\
\hline d & $68 \pm 1.7_{c}$ & $32 \pm 0.8_{\mathrm{cd}}$ & $1088 \pm 27.2_{c}$ & $36 \pm 0.9_{\mathrm{e}}$ & $16.1 \pm 0.4_{\mathrm{at}}$ & b $30 \pm 0.8_{c}$ & $31 \pm 0.8_{\mathrm{b}}$ & $4 \pm 0.1_{\mathrm{a}}$ \\
\hline $\mathrm{e}$ & $60 \pm 1.5_{c}$ & $25 \pm 0.6_{\mathrm{c}}$ & $750 \pm 18.8_{c}$ & $38 \pm 1_{\mathrm{e}}$ & $19.7 \pm 0.5$ & b $27 \pm 0.7 \mathrm{c}$ & $29.7 \pm 0.7_{b}$ & $7 \pm 0.2_{\mathrm{a}}$ \\
\hline $63 \mathrm{a}$ & $123 \pm 3_{\mathrm{f}}$ & $61 \pm 1.5_{\mathrm{f}}$ & $3751.5 \pm 93.8_{\mathrm{f}}$ & $78 \pm 2_{\mathrm{f}}$ & $16.2 \pm 0.4_{\mathrm{at}}$ & $63 \pm 1.6_{f}$ & $25 \pm 0.6_{\mathrm{ab}}$ & $33 \pm 0.8 \mathrm{~b}$ \\
\hline $\mathrm{b}$ & $132 \pm 3.3_{\mathrm{f}}$ & $68 \pm 1.7_{\mathrm{f}}$ & $4488 \pm 112.2_{\mathrm{f}}$ & $84 \pm 2.1_{\mathrm{f}}$ & $15.3 \pm 0.4_{\mathrm{at}}$ & b $70 \pm 1.8_{\mathrm{f}}$ & $23 \pm 0.6_{\mathrm{ab}}$ & $35 \pm 0.9 \mathrm{~b}$ \\
\hline $\mathrm{c}$ & $103 \pm 2.6_{\text {ef }}$ & $49 \pm 1.2_{\mathrm{ef}}$ & $2523.5 \pm 63.1_{\text {ef }}$ & $73 \pm 1.8_{\mathrm{f}}$ & $12.3 \pm 0.3_{\mathrm{at}}$ & $60 \pm 1.5_{\mathrm{f}}$ & $19.2 \pm 0.5_{\mathrm{a}}$ & $27 \pm 0.7 \mathrm{~b}$ \\
\hline d & $96 \pm 2.4_{\text {ef }}$ & $47 \pm 1.2_{\mathrm{ef}}$ & $2256 \pm 56.4_{\text {ef }}$ & $63 \pm 1.6_{\mathrm{ef}}$ & $9.2 \pm 0.2$ & a $52 \pm 1.3_{\mathrm{ef}}$ & $14.6 \pm 0.4_{a}$ & $24 \pm 0.6 \mathrm{~b}$ \\
\hline $\mathrm{e}$ & $74 \pm 1.9_{\mathrm{e}}$ & $39 \pm 1_{\mathrm{e}}$ & $1443 \pm 36.1_{\mathrm{e}}$ & $45 \pm 1.1_{\mathrm{e}}$ & $21.3 \pm 0.5$ & $36 \pm 0.9_{\mathrm{e}}$ & $27.8 \pm 0.7_{\mathrm{b}}$ & $12 \pm 0.3_{\mathrm{ab}}$ \\
\hline
\end{tabular}

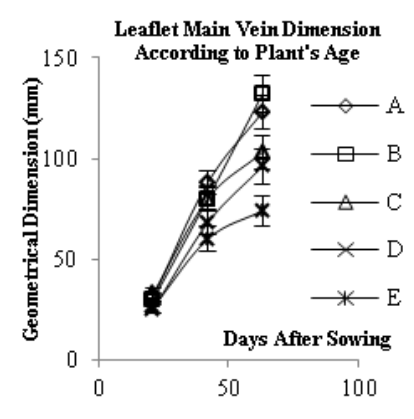

a.

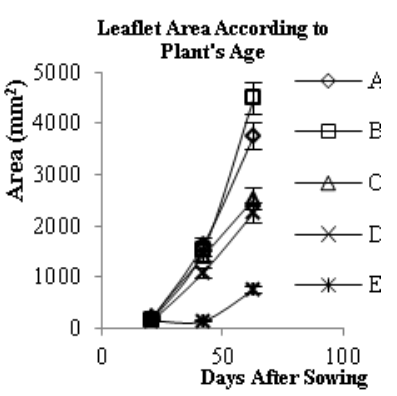

c.

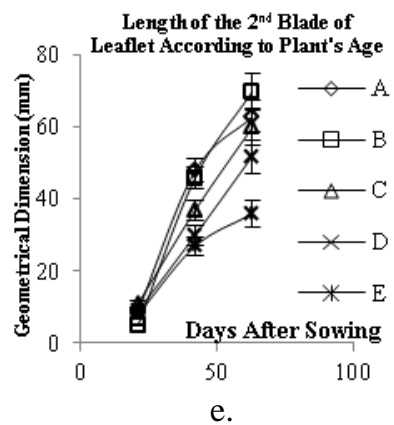

Fig. 4. Geometrical dimensions of the leaflets from the terminal compound leaves of the tomato plants. Five leaflets were selected from terminal compound leaf (See Fig. 1), and their geometrical dimensions progressed along the growth of the plants, as seen on the dimension of leaflets' veins (a); width (b); area (c); length of the $1^{\text {st }}$ leaf-blade (d); length of the $2^{\text {nd }}$ leafblade (e); and petiole (f). 
From Fig. 4, it was observed that the dimensions of the geometric features of the leaflet have linear relationship with the plant's age, such as the length of the main veins of the leaflets (Fig. 4a); leaflets width (Fig. 4b); as well as the length of the blades (Fig. 4d and Fig. 4e) for some leaflets.

In Fig. 4 it was also observed that the area of the leaflets (Fig. 4c) and the length of its petiole (Fig. 4f) grow exponentially, in contrast to others geometric features of the leaflets.

However, the selection of geometric features of the leaflet as parameter for the multimodal biometric analysis of tomato plants cannot be used as a reference solely based on the relationships between the trends of the size of the leaf with the age of the plant. To correctly determine which geometric features significantly contribute to determine the age of the plants, a further statistical analysis was performed, namely the PCA.

TABLE III

DESCRIPTIVE StATISTICS OF THE GEOMETRIC FEATURES OF THE LEAVES

\begin{tabular}{lrrrrrr} 
& \multicolumn{6}{c}{ Days after sowing (DAS) } \\
\cline { 2 - 7 } & \multicolumn{6}{c}{ Std. } \\
\cline { 2 - 7 } & Mean Dev. ( $\delta$ ) Mean & $\delta$ & Mean & $\delta$ \\
\hline Main Vein & 29.0 & 3.2 & 75.2 & 10.4 & 105.6 & 21.3 \\
Leaflet Wide & 12.2 & 1.2 & 33.4 & 4.9 & 52.8 & 10.8 \\
Leaflet Area & 178.1 & 34.7 & 1277.2 & 332.0 & 2892.4 & 1128.8 \\
Blade1 Length & 14.6 & 2.7 & 48.8 & 11.1 & 68.6 & 14.2 \\
Blade1 Angle & 14.5 & 5.3 & 12.4 & 5.0 & 14.9 & 4.2 \\
Blade2 Length & 8.4 & 2.0 & 37.6 & 8.7 & 56.2 & 12.1 \\
Blade2 Angle & 28.1 & 8.7 & 22.2 & 7.1 & 21.9 & 4.8 \\
Petiole & 2.8 & 2.4 & 2.2 & 3.0 & 26.2 & 8.4 \\
\hline
\end{tabular}

Using the geometrical features of the leaflets as input variables, the PCA was performed based on the plants age upon observation. Based on the univariate descriptive analysis, as shown in Table II, indicated the average of leaflets geometrical features and their difference, measured by the standard deviation between data.

The data extraction of the PCA analysis was performed by utilizing the KMO and Bartlett's test of sphericity and the correlation analysis reproduced based on the anti-image and inverse correlation to assess the significant level of the features. For the selection of the principal components, the Eigenvalue had to be greater than one; therefore, only significant components were selected. The results were rotated using a Vari-max factor analysis rotation to show which features were correlated between each other, and thus can be represent by a single principal component.

Number of the components required to explain the total variation of the geometric features of the leaflets depend on the age of the plants upon observation. Described by Fig. 5, the scree plot showed that during the initial stage of the plants, the leaflets geometric features can be explained by two principal components. These numbers of the components determined by the Eigenvalue from the PCA analysis of the geometrical features data. When the plants reached the mid-age (42 days) of vegetative stages, the principal component required to explain the variation of the data, can be assigned by a single component. However, when the plants enter the generative stage, approximately 60 DAS, the principal components required to explain the variance of the data increased to two components.

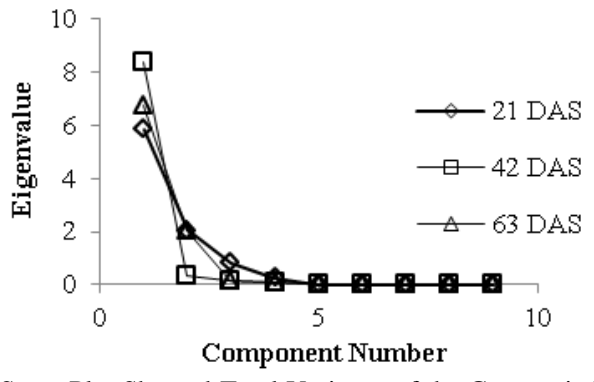

Fig. 5. The Scree Plot Showed Total Variance of the Geometric Features of the Leaflets as Explained Based on the Number of the Components and Eigenvalues.

Based on these differences of principal components required in each developmental stage of the plants, the biometric analysis of the tomato plants hence required discrete approached, meaning, the analysis cannot be generalized for the whole development stages of the plants, rather it need to be specified by age.

The first principal component for determining the multimodal biometrics of tomato plant in the initial vegetative state (21 DAS) consists of five geometric features (Fig. 6), namely main vein; blade1 length; leaflet area; leaflet width; and blade2 length. The second principal component consists of four geometrical features, the petiole; leaflet position; blade1 angle; and blade 2 angle.

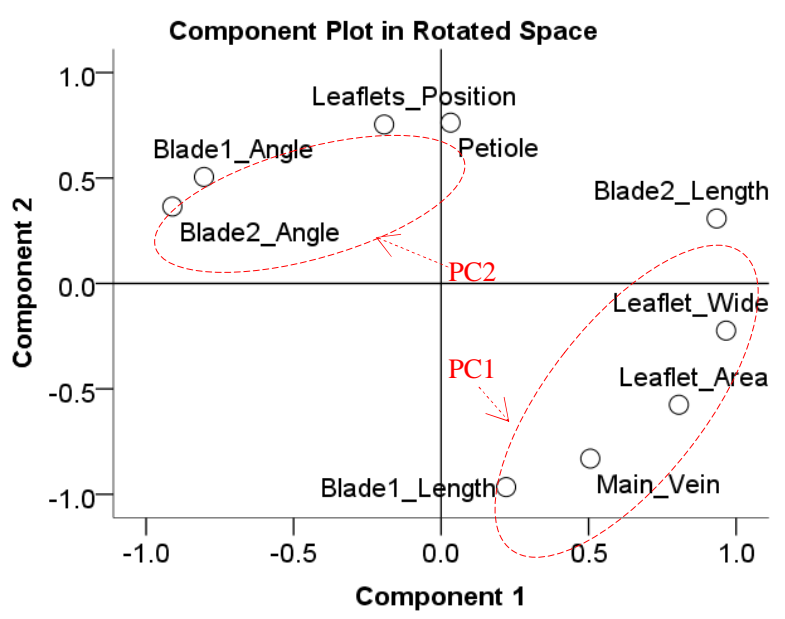

Fig. 6. The Component Plot in Rotated Space from PCA of the geometrical features of the leaflets from the 21 days old tomato plants.

Entering middle vegetative stages (42 DAS), a single principal component enable to explain the multimodal biometric analysis for samples age determination. The component consisted of all the geometrical features of the leaflets, namely: Blade1_Angle; Leaflet_Area; Main_Vein; Leaflets_Position; Blade2_Length; Petiole; Blade1_Length; Leaflet_Wide; and Blade2_Angle. All of these geometrical features contributes evenly to the multimodal biometrics analysis and equally important to determine the plants age.

Upon reaching the generative stage, the plants age was around 60 days. When observations were performed on the 63 DAS, most of the sample plants have produced flowers. At this age, the geometrical features of the plants' leaflets could be categorized into two principal components (Fig. 7). The first principal component for multimodal biometrics of 
tomato plants consists of seven geometrical features, of the leaflets, which are: Leaflet-Wide, Leaflet_Area, Main_Vein, Blade1_Length, Blade2_Length, and Petiole. The second principal component for multimodal biometrics of tomato plants comprised of two geometrical features, Blade2_angle; and Blade1_Angle.

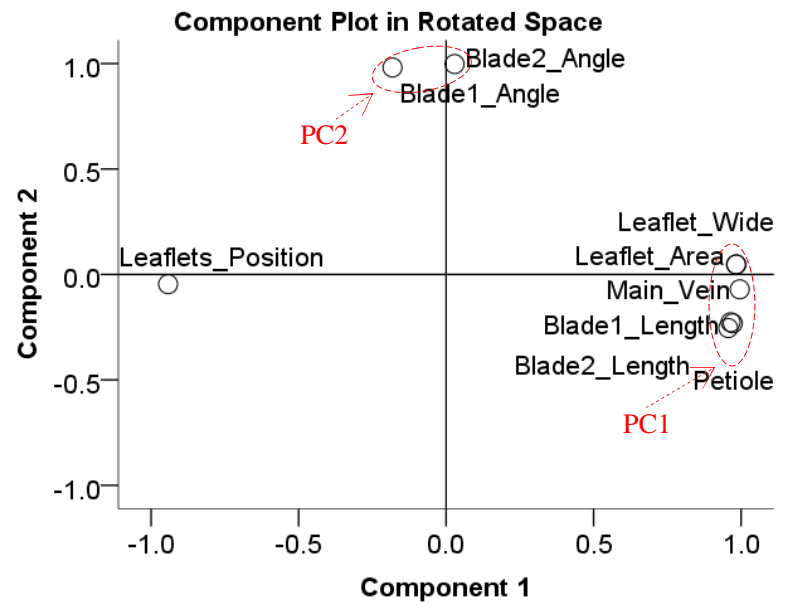

Fig. 7. The Component Plot in Rotated Space from PCA of the geometrical features of the leaflets from the 63 days old tomato plants.

In contrast to the principal components of the plants when observed at $21 \mathrm{DAS}$, the geometrical features of the leaflets at 63 DAS were less vary, observed by their positions on the graphs (Fig. 7). These conditions suggest that the differences between the features were reduced and converged, therefore they may instead represent as a single variable. However, since the importance of these features for age determination of the plants were different among components, several features cannot be represent with one feature only, thus, to reduce the factor in the analysis, features with similar contribution to the analysis represent by a principal component.

Although the number and values of principal component at three age stages of the plants were differ (Fig. 8), where 21 and 63 DAS observation resulting of two principal components, and 42 DAS observation resulting single component, and the leaflets position influenced the components value, in general, the first component mainly contribute as an important factor when multimodal biometrics analysis were performed to determine the plants' age.

Therefore, in this study, the multimodal biometrics analysis for determining the plants' age performed using the first principal component, to explain the relationships between geometrical features of the leaflets, their position in compound leaves and the plants age.

Based on the geometric features data of the samples, leaflets B (Fig. 1) have largest dimensions, while leaflets E were among the smallest. This phenomenon suggests that the terminal leaflets was not the largest in the primary compound leaves of tomato plants, instead it is the second leaflet which has greater dimensional size. In general, the dimensional size of the leaflets in compound leave of the tomato plants may be shorted as B-A-C-D-E from the largest to the smallest size.

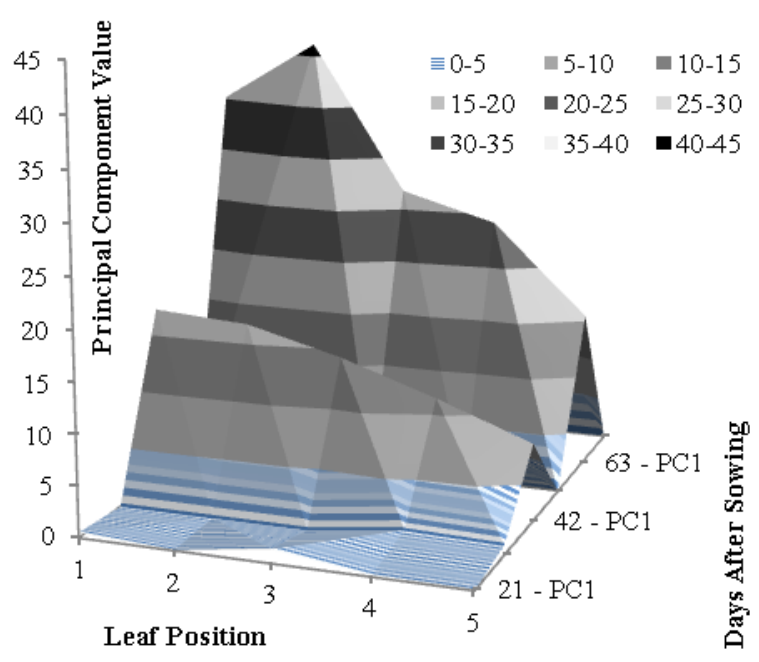

Fig. 8. A three axis graph explaining the relationship between the first principal components values, leaflets positions, and the observation time (plants age). The graph suggested positive correlation of the principal component values with the plants age, and negative correlations between leaflets positions and the components values.

The first principal components of the leaflets' geometrical features can be calculated based on the coefficients produced by the statistical software (Table III). Since there are two developmental stages of the plants when they grow; the generative and vegetative stage, the principal components should be calculated based on the plants' state, accordingly. The coefficients as presented in Table III explained the contribution of each geometrical feature to the Principal Component values. The calculation of the principal component can be done using the following formula:

$$
P C 1-i=a_{1} b_{1}+a_{2} b_{2}+\cdots+a_{t 1} b_{t 1}
$$

Where $i$ is the leaflet position on the compound leaves, $a$ is the coefficient value of the feature, and $b$ is the geometrical feature dimension of the leaflet.

TABLE III

COEFFICIENT OF PRINCIPAL COMPONENTS FOR GEOMETRICAL FEATURES OF THE LEAFLETS BASED ON THE PLANTS' DEVELOPMENT STAGES

\begin{tabular}{lrr}
\multicolumn{3}{c}{ Component Score Coefficient Matrix ${ }^{\text {a }}$} \\
\cline { 2 - 3 } & \multicolumn{2}{c}{ Plant's Stage } \\
\hline Legetative & Generative \\
\hline Main_Vein & 0.060 & -0.151 \\
Leaflet_Wide & 0.023 & 0.153 \\
Leaflet_Area & 0.258 & 0.157 \\
Blade1_Length & 0.154 & 0.157 \\
Blade1_Angle & -0.085 & 0.139 \\
Blade2_Length & -0.164 & 0.027 \\
Blade2_Angle & 0.332 & 0.136 \\
Petiole & -0.219 & 0.061 \\
\hline${ }^{a}$ Extraction Method: Principal Component Analysis. \\
Rotation Method: Varimax with Kaiser Normalization.
\end{tabular}

Based on the value of the principal component of the leaflets, and their positions, the age of the observed plants (measured by days after sowing) can be determined using the following equations: 


$$
\begin{aligned}
& D A S_{1}=1.2108(P C 1-A)+20.594 \\
& D A S_{2}=0.981(P C 1-B)+23.493 \\
& D A S_{1}=1.653(P C 1-C)+18.553 \\
& D A S_{4}=1.7381(P C 1-D)+21.35 \\
& D A S_{5}=2.5827(P C 1-E)+22.637
\end{aligned}
$$

The equation 2 until 6 is for the age determination of the leaflets position A until E, respectively. The developed mathematical models to determine tomato plants' age based its leaflets geometrical features from the primary compound leaves have coefficient of correlation higher than 0.99 (Fig. 9) which indicate the exceptional accuracy of the models.

Nevertheless, these developed models only applicable to the tomato plants of this particular cultivar, others models should be developed for other tomato cultivar using similar principal, or by means of machine visions and spectroscopy[25-38].

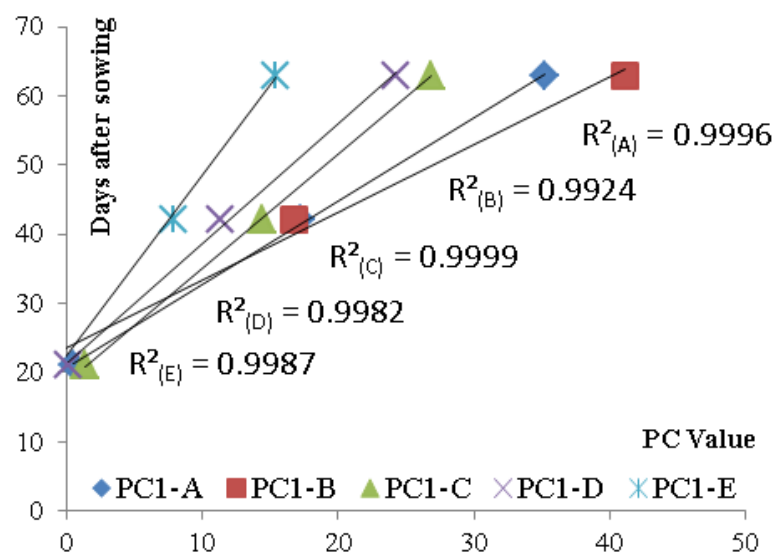

Fig. 9. Mathematical models on the plants age based on the multimodal biometrics analysis of the first principal component, represented several leaflets geometrical values. The models adjusted according to the leaflets position on the primary compound leaves of the tomato plants..

\section{CONCLUSIONS}

The age and state of the tomato plants in this study can be determined non-destructively based on its multimodal biometrical characteristics. Five models were developed to estimate plants age, according to the leaflets position on the primary compound leaves. The phenotypic were done by measuring the geometrical features of the selected leaflets and performed PCA, in order to retrieve the principal component values. These values were integrated into the models to get the age determination results. Developed models accurately estimated the plants' age with coefficient of correlation higher than 0.99 .

\section{ACKNOWLEDGMENT}

The author would like to thank to the Faculty of Agricultural Technology of the Andalas University for providing research funding for this study, under DIPA scheme (Contract No. 01r/PL/DF-DIPA/FATETA-2015). Author acknowledges the support given by his students during the commencement of this study.

\section{REFERENCES}

[1] BPS. 2014. Tomatoes Production by Province, 2010-2014. Indonesian statistical body and directorate general of horticulture, Ministry of agriculture, Indonesia.

[2] Blanco, F. F., and Folegatti, M.V. 2003. A new method for estimating the leaf area index of cucumber and tomato plants. Horticultura Brasileira, Brasília, 21(4):666-669, outubro/dezembro.

[3] Reddy, J., Rao L.M., and Nachappa, M.N. 2012. A Study On Multimodal Biometric Systems And Taxonomic Identification Of Plant Species. International Journal of Advanced Computer and Mathematical Sciences. Vol 3, Issue 2, pp 250-256.

[4] Jain, A. K., A. Ross and S. Prabhakar. 2004. An introduction to biometric recognition. IEEE Transactions on Circuits and Systems for Video Technology, vol. 14, pp. 4-20.

[5] Lhotka, J.M., Loewenstein, E.F. 2006. Indirect measures for characterizing light along a gradient of mixed-hardwood riparian forest canopy structures. Forest Ecol. Manage., 226(1-3): 310-318.

[6] Feng, H., T. Zhang, Y. T. Shi, W. J. Wang, and W. H. Wang. 2010 Research of plant type and light distribution of tomatoes determined by imaging technology. African Journal of Agricultural Research Vol. 5(14), pp. 1860-1867, 18 July, DOI: 10.5897/AJAR09.202.

[7] Papadopoulos, A.P., and Pararajasingham, S. 1997. The influence of plant spacing on light interception and use in greenhouse tomato (Lycopersicon esculentum Mill.): Rev. Sci. Hortic., 69(1-2): 1-29.

[8] Higashide, T. 2009. Light interception by tomato plants (Solanum lycopersicum) grown on a sloped field. Agric. Forest Meteorol., 149(5): 756-762.

[9] Feng H, Wang W.H., Xu N., Lu B., Zhang T., and Chen H.B. 2008. Inheritance of several plant type characters in truss tomato. Agric. Sci. China 7(5):535-541.

[10] Foley J.D., Dam A., Feiner S.K., Hughes J.F., and Phillips R.L. 1993. Introduction to Computer Graphics. Addison-Wesley Professional.

[11] Jonckheere I, Fleck S, Nackaerts K, Muysa B, Coppin P, Weiss M, Baret F. 2004. Review of methods for in situ leaf area index determination Part I. Theories, sensors and hemispherical photography. Agric. Forest Meteorol., 121(1-2): 19-35.

[12] Cescatti, A. 2007. Indirect estimates of canopy gap fraction based on the linear conversion of hemispherical photographs Methodology and comparison with standard thresholding techniques. Agric. Forest Meteorol., 143(1-2): 1-12.

[13] Takayama, K., Nishina, H., Iyoki, S., Arima, S., Hatou, K., Ueka, Y., and Miyoshi Y. 2011. Early detection of drought stress in tomato plants with chlorophyll fluorescence imaging: practical application of the speaking plant approach in a greenhouse. 18th IFAC World Congress, Milano, Italy. August 28 - September 2, 1785-1790.

[14] Takayama, K., Nishina, H., Mizutani, K., Arima, S., Hatou, K., and Miyoshi, Y. 2010. Chlorophyll fluorescence imaging for health condition monitoring of tomato plants in greenhouse. Acta Hort.

[15] Raza S-e-A, Prince G, Clarkson JP, Rajpoot NM. 2015. Automatic Detection of Diseased Tomato Plants Using Thermal and Stereo Visible Light Images. PLoS ONE 10(4): e0123262. doi:10.1371/journal.pone. 0123262

[16] Raza SEA, Smith HK, Clarkson GJJ, Taylor G, Thompson AJ, Clarkson J,. 2014. Automatic Detection of Regions in Spinach Canopies Responding to Soil Moisture Deficit Using Combined Visible and Thermal Imagery. PLoS ONE. 2014 Jan; 9(6):e97612. doi: 10.1371/journal.pone.0097612 PMID: 24892284

[17] Oerke E.C., Steiner U., Dehne H.W., and Lindenthal M. 2006. Thermal imaging of cucumber leaves affected by downy mildew and environmental conditions. Journal of Experimental Botany. Jan; 57(9):2121-32. doi: 10.1093/jxb/erj170 PMID: 16714311

[18] Oerke EC, Fröhling P, Steiner U. 2011. Thermographic assessment of scab disease on apple leaves. Precision Agriculture. Dec; 12(5):699-715. doi: 10.1007/s11119-010-9212-3

[19] Lindenthal M, Steiner U, Dehne HW, and Oerke EC. 2005. Effect of downy mildew development on transpiration of cucumber leaves visualized by digital infrared thermography. Phytopathology. 2005 Mar; 95(3):233-40. doi: 10.1094/PHYTO-95-0233 PMID: 18943115

[20] Chitwood, DH., R. Kumar, L.R. Headland, A. Ranjan, M.F. Covington, Y. Ichihashi, D. Fulop, J.M. Jiménez-Gómez, J. Peng, J.N Maloof, and N.R. Sinhaa. 2013. A Quantitative Genetic Basis for Leaf Morphology in a Set of Precisely Defined Tomato Introgression Lines. The Plant Cell, July Vol. 25: 2465-2481. 
[21] Wu, S.G., F.S. Bao, E.Y. Xu, Y.X. Wang and Y.F. Chang et al., 2007. A leaf recognition algorithm for plant classification using probabilistic neural network. Proceedings of the IEEE 7th International Symposium on Signal Processing and Information Technology, Dec. 15-18, IEEE Xplore Press, Giza, pp: 11-16. DOI: 10.1109/ISSPIT.2007.4458016

[22] Fotopoulou, F., N. Laskaris, G. Economou and S. Fotopoulos, 2011. Advanced leaf image retrieval via Multidimensional Embedding Sequence Similarity (MESS) method. Patt. Anal. Appli. DOI: 10.1007/s10044-011-0254-6

[23] Valliammal, N. and S.N. Geethalakshmi, 2012. A novel approach for plant leaf image segmentation using fuzzy clustering. Int. J. Comput. Applic., Foundat. Comput. Sci., 44: 10-20. DOI: 10.5120/6322-8669.

[24] Iwata, H., and Y. Ukai. 2002. SHAPE: A Computer Program Package for Quantitative Evaluation of Biological Shapes Based on Elliptic Fourier Descriptors. The Journal of Heredity 2002:93(5): 384-385

[25] Makky M., Herodian S., and Subrata I.D.M., 2004. Design and Technical test of visual sensing system for palm oil harvesting robot. Proc. Int. Seminar on Advanced Agric. Eng. Farm Work Operation, August 25-26, Bogor, Indonesia. pp.582-592.

[26] Thoriq A., Herodian S., Makky M., Sutejo A., and Cherie D. 2012 Application of Non-destructive spectroscopy technique for determination of Oil Palm Fresh Fruits Bunch (FFB) maturity. The role of agricultural engineering to support food and energy security with environmental insight: Proc. of ISAE national seminar, ed. Hendrawan Y., Al Riza D.F., Dewi S.R., Sugiarto Y., Ubaidillah, and Fatchurrahman D. Brawijaya University, Malang, 30 Nov.-2 Dec. Indonesia. pp.178-185.

[27] Cherie D., Herodian S., Makky M., Mandang T., Ahmad U., and Thoriq A. 2012. Application of Photogrametric for oil palm (Elaeis guineensis Jacq) Fresh Fruits Bunch (FFB) ripeness. The role of agricultural engineering to support food and energy security with environmental insight: Proc. of ISAE national seminar, ed. Hendrawan Y., Al Riza D.F., Dewi S.R., Sugiarto Y., Ubaidillah, and Fatchurrahman D. Brawijaya University, Malang, 30 Nov.-2 Dec. Indonesia. pp. 166-177.

[28] Makky M., Herodian S., Cherie D., Ahmad U., and Mandang T. 2012. Spectroscopy and Photogrammetric techniques for assessing physicochemical properties of oil palm (Elaeis guineensis Jacq) Fresh Fruits Bunch (FFB). Proc. Research Dissemination Seminar, International Convention Center (IICC) - Bogor Agricultural University,, Bogor, 10-11 December, Indonesia.
[29] Makky M., Soni P., and Salokhe V.M. 2012. Machine Vision Application in Indonesian Oil Palm Industry. The Asian Forum of 2012 CSAM (Chinese Society for Agricultural Machinery) International Academic Annual Meeting. "Innovation, Win-win, Development”. October 27th -30th, Hangzhou, China.

[30] Makky M. and Soni P., 2013. Towards sustainable green production: exploring automated grading for oil palm fresh fruit bunches (FFB) using machine vision and spectral analysis. Int. J. Advanced Sci. Eng. Information Technol., 3(1), 1-7.

[31] Makky M. and Soni P., 2013. Development of an automatic grading machine for oil palm fresh fruit bunches (FFBs) based on machine vision. Computers Electronics Agric., 93, 129-139.

[32] Makky M. and Soni P., 2014. In situ quality assessment of intact oil palm fresh fruit bunches using rapid portable non-contact and nondestructive approach. J. Food Eng., 120, 248-259.

[33] Makky M., Soni P., and Salokhe V.M., 2014. Automatic nondestructive quality inspection system for oil palm fruits. Int. Agrophys., 28, 319-329.

[34] Makky M., Paschalidis K.A., Dima K., and Mangganaris A. 2014 Harnessing Untapped Bio-Ethylene Sources from Tomatoes Climacteric Effluent. Proc. International Conference on Agricultural, Environmental and Biological Sciences (AEBS-2014) April 24-25, Phuket, Thailand. pp. 27-32.

[35] Makky M., Paschalidis K.A., Dima K., and Mangganaris A. 2014. A New Rapid Gas Chromatographic Method for Ethylene, Respirational, and Senescent Gaseous Production of Climacteric Fruits Stored in Prolonged Low Temperature. Proc. International Conference on Agricultural, Environmental and Biological Sciences (AEBS-2014) April 24-25, Phuket, Thailand. pp. 21-26.

[36] Makky M., Paschalidis K.A., Dima K., and Mangganaris A., 2015. Tomato Fruits (Solanaceae Lycopersicon esculentum Mill.) Feedback Mechanism in The Presence of Exogenous Ethylene under Prolonged Chilling Temperature Storage. Journal of Nutrition \& Pharmacy Research, 1(1):4-12. International Institute of science and industry research, Australia.

[37] Cherie D., Herodian S., Ahmad U., Mandang T., and Makky M. 2015. Optical Characteristics of Oil Palm Fresh Fruits Bunch (FFB) Under Three Spectrum Regions Influence for Harvest Decision. IJASEIT 5(3): 104-112

[38] Cherie, D., Herodian, S., Mandang, T., Ahmad, U., and Makky, M. 2015. Camera-Vision Based Oil Content Prediction for Oil Palm (Elaeis Guineensis Jacq) Fresh Fruits Bunch at Various Recording Distances. IJASEIT 5(4): pages: 314-322. 